\title{
Neurofibromatosis associated with retinoblastoma: case report
}

\author{
BERATI HASANREISOGLU, MERAL OR, AND HALUK AKBATUR
}

From the Department of Ophthalmology, Gazi University Medical Faculty, Ankara, Turkey

SUMMARY A case of neurofibromatosis is presented in a 3-year-old male with leucokoria in his left eye. Enucleation was performed, and on pathological examination the mass filling the globe proved to be retinoblastoma. We believe ours to be the first reported case of this rare association.

Neurofibromatosis is an irregularly transmitted autosomal dominant, neurocutaneous, hereditary disorder that has incomplete penetrance and variable expressivity. It results from dysplasia of neuroectodermal and mesodermal tissues. Glial and melanocytic hamartomas of the retina and uveal tract can be found in patients with this disease.

Our case is a rare association of neurofibromatosis and retinoblastoma - a malignant tumour of neuroectodermal origin-in a 3-year-old male. It is among the retinal tumours reported in association with neurofibromatosis.

\section{Case report}

A 3-year-old boy was seen in our outpatient department on 20 February 1986 because of leucokoria in his left eye (Fig. 1). His parents had been aware of

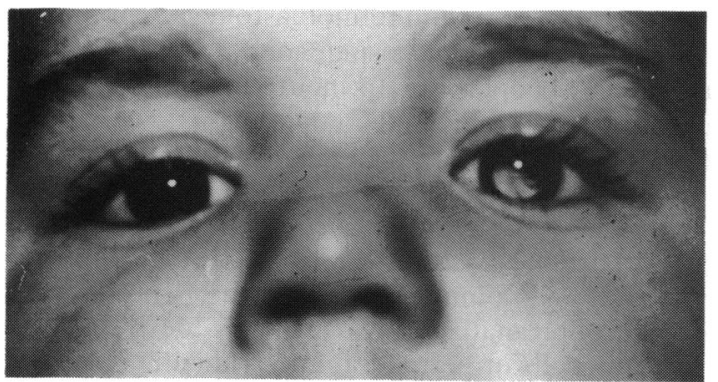

Fig. 1 Leucokoria in the left eye.

Correspondence to Dr Meral Or, Alaçam sokak, Onlar apt 37/5, A Ayrancı, Ankara, Turkey.

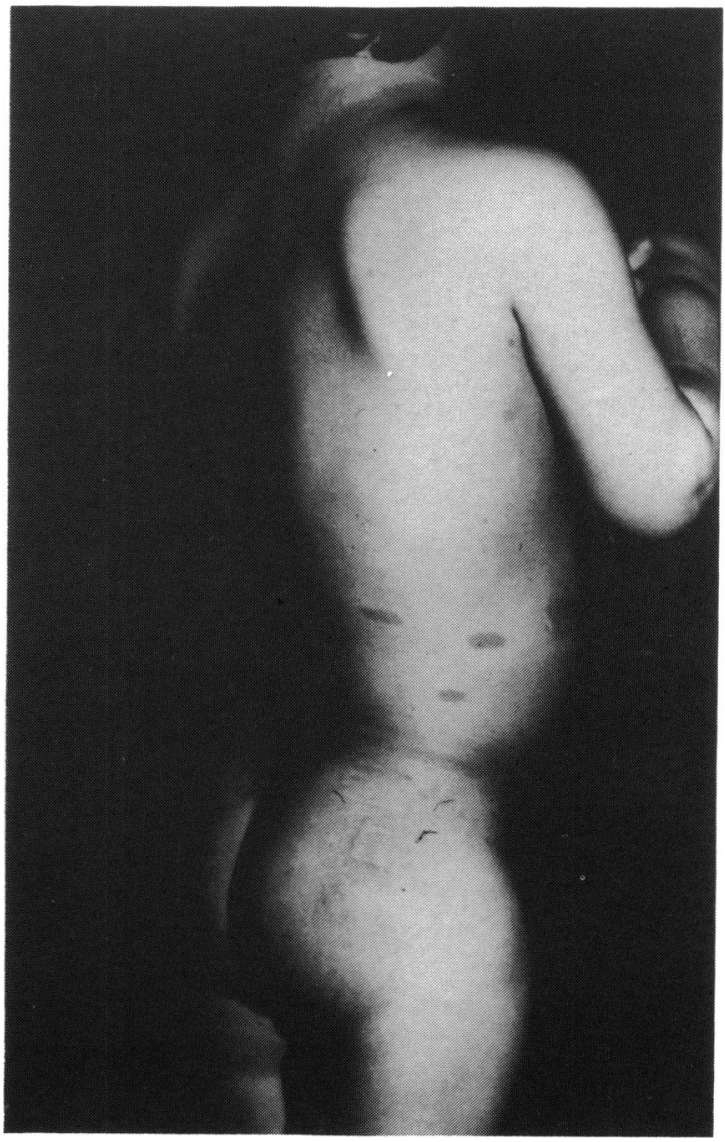

Fig. 2 Café-au-lait spots on the body. 
Fig. 3 The family tree. $\square$ Male. $\bigcirc$ Female. $\square$ Male with neurofibromatosis. D Female with neurofibromatosis. Proband with neurofibromatosis and retinoblastoma. $\mathrm{l}=$ died.

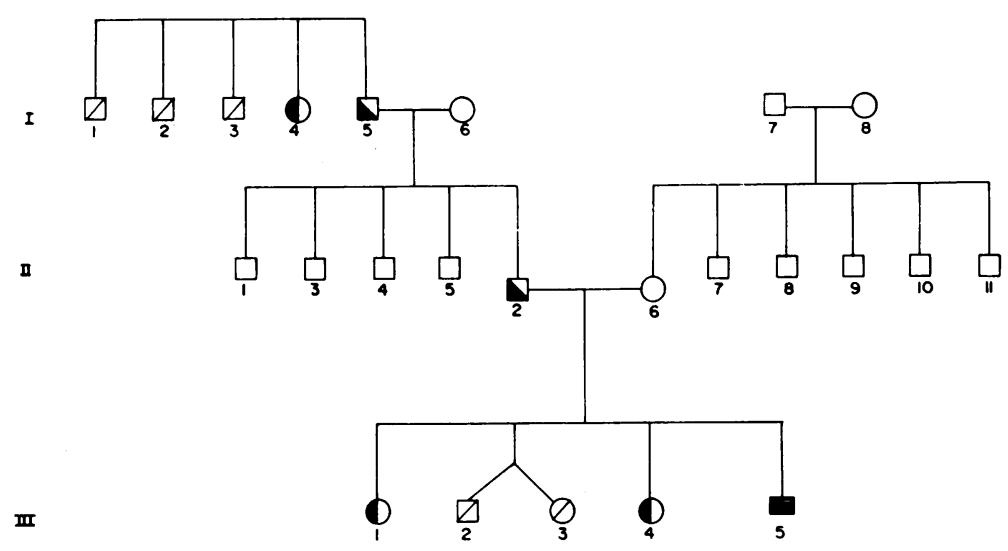

this white pupillary sign for about 1.5 months, but they did not consider it important.

On systemic examination he had large and small café-au-lai spots over the trunk and upper right arm of his body (Fig. 2), and there was a family history of neurofibromatosis (Fig. 3).

Examination of the left eye disclosed a pinkish white mass without pigmentation filling the entire globe, clinically suggesting retinoblastoma. The retina was detached and could be seen in the

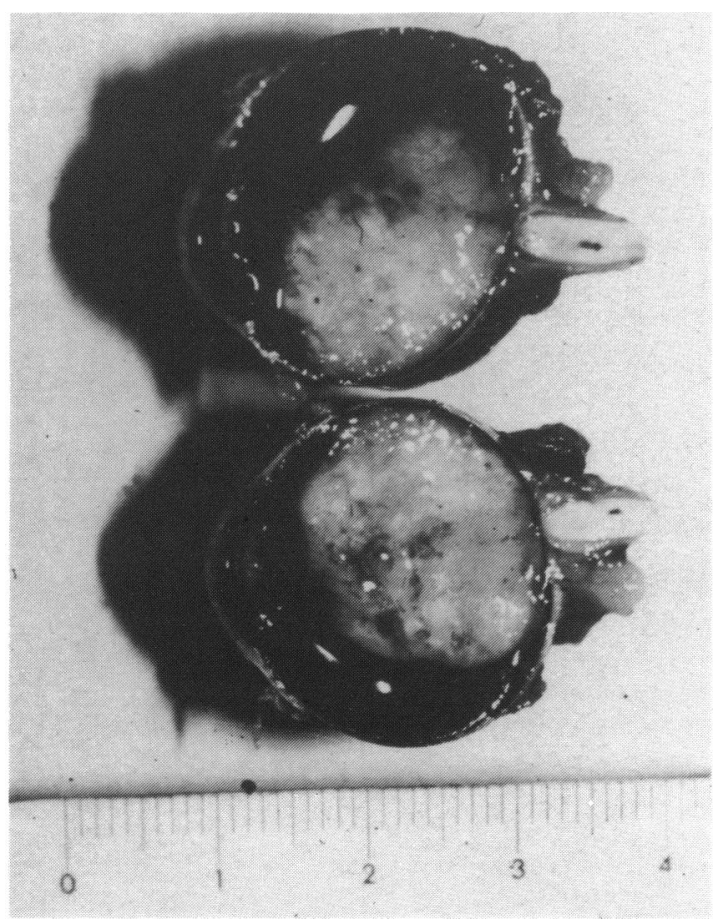

Fig. 4 Gross specimen of retinoblastoma. pupillary area. The visual acuity could not be measured. The cornea and lens were clear. Radiographic examination did not show any calcification. $A$ and $B$ mode ultrasonographic examination supported the diagnosis, showing a solid mass behind the lens. Chromosomal analysis revealed a normal karyotype.

Enucleation was performed, and the bulbus with $10 \mathrm{~mm}$ of optic nerve behind the globe was removed eight days later under general anaesthesia. Examination of the fundus of the other eye showed no abnormality.

The left bulbus was of normal size, and a tumour continuing with the retina grew towards vitreous, which showed large areas of necrosis (Fig. 4). Histopathologically, the cells that form the neoplasm had large hyperchromatic nuclei with minimal amounts of cytoplasm. In some areas these cells were attached to each other, forming rosettes (Fig. 5). The final diagnosis was retinoblastoma. The optic disc was found to be intact.

\section{Discussion}

Neurofibromatosis and retinoblastoma are both considered to be predisposing conditions to second malignant neoplasms. In neurofibromatosis, dysplasia, hyperplasia, and neoplasia of a variety of tissues are encountered, and the gene for this disease could be regarded as an example of a cancer gene.' Three factors highly suggestive of the malignant potential of the disease are unusual tumours, multiple tumours, and young age at diagnosis. ${ }^{2}$ The tumours in neurofibromatosis are generally derived from Schwann cells of peripheral and cranial nerves, and glial cells of the central nervous system. Malignant neural and more rarely melanocytic tumours occur in approximately $0 \cdot 3 \%$ of the patients. ${ }^{3-6}$

Our case presents an association of retinoblastoma, 


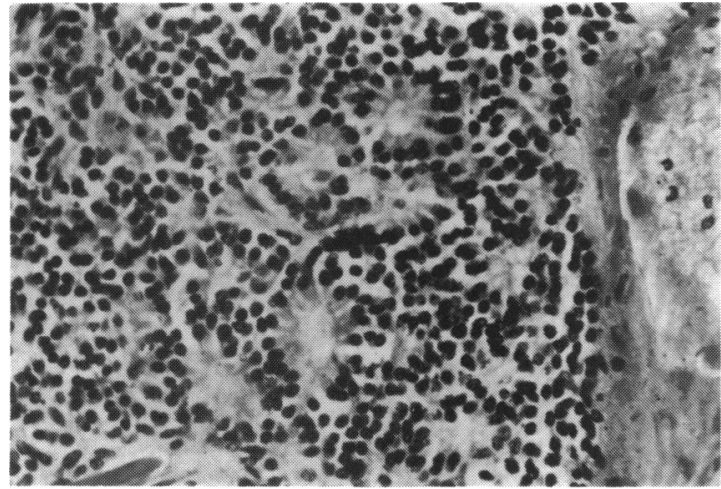

Fig. 5 Histopathological section of the tumour. FlexnerWintersteiner rosettes are visible. Haematoxylin and eosin.

a tumour of neuroectodermal origin, ${ }^{7}$ with neurofibromatosis. Although this may be a chance association, it is not surprising, since tumours of neural crest and non-neural crest origin have been reported to occur in neurofibromatosis, and the disease is considered to be a predisposing cause of second malignant neoplasms.

Schwannoma, neurilemmoma, acoustic neuroma, optic glioma, meningioma, ganglioneuroma, naevus of Ota, and choroidal melanoma, all tumours of neural crest derivatives - that is, Schwann cells, glial cells, and melanocytes-have been reported in association with neurofibromatosis. ${ }^{89}$ Wilms' tumour, acute leukaemia, rhabdomyosarcoma, neuroblastoma, and malignant fibrous histiocytoma áre other non-neural crest malignancies reported in cases of neurofibromatosis. ${ }^{12}$

It has also been reported that second tumours may follow radiation treatment or chemotherapy, or be unassociated with radiation therapy, mostly in patients with bilateral retinoblastomas. The reported tumours are bone sarcoma, soft tissue sarcoma, leukaemia, lymphoma, brain tumour, skin carcinoma, melanoma, histiocytosis $\mathrm{X}$. Those that cannot be related to radiation therapy imply a common chromosomal origin with retinoblastoma."

Our case was a unilateral retinoblastoma with no family history and normal chromosomal findings. It is known that certain unilateral sporadic cases of retinoblastoma are germinal mutations, and $10 \%-15 \%$ of these patients transmit the disease to their offspring. "If this is so with our case, it leads us to believe that the genetic abnormality leading to neurofibromatosis played some part in the development of the retinal tumour.

A retinal tumour in neurofibromatosis is likely to be an astrocytoma, though this is less frequently seen in neurofibromatosis than in tuberous sclerosis. ${ }^{12}$ Consequently we recommend that a retinal tumour in neurofibromatosis should be examined and followed up carefully, because if it is a retinoblastoma it can be cured by methods other than enucleation if diagnosed early.

\section{References}

1 Wertelecki W, linuma K, Bentley HP. Non-neural malignancy complicating neurofibromatosis in two relatives. Cancer Genet Cytogenet 1985; 18: 87-9.

2 Warrier RP, Kini KR, Raju U, Shumacher B, Wu K. Neurofibromatosis and malignancy. Clin Pediatr 1985; 24: 584-5.

3 Brownstein S, Little JM. Ocular neurofibromatosis. Ophthalmology 1983; 91: 1595-9.

4 Font RL, Ferry AP. The phakomatoses. Int Ophthalmol Clin 1972; 12: 1-5.

5 Yanoff M, Fine BS. Ocular pathology. A text and atlas. 2nd ed. Philadelphia: Harper and Row, 1982: 33-9.

6 Wiznia RA, Freedman JK, Mancini AD, Shields JA. Malignant melanoma of the choroid in neurofibromatosis. Am J Ophthalmol 1978; 86: 684-7.

7 Russel DS, Rubinstein LJ. Pathology of tumors of the nervous system. 4th ed. Edinburgh: Constable, 1977: 48-55, 299-307.

8 Croxatto JO, Charles DE, Malbran ES., Neurofibromatosis associated with nevus of Ota and choroidal melanoma. Am J Ophthalmol 1981: 92: 578-80.

9 Hope DG, Mulvihill JJ. Malignancy in neurofibromatosis. In: Richard VM, Mulvihill JJ, eds. Advances in neurology. New York: Raven Press, 1981: 33-56.

10 Meadows AT, Baum E, Fossati-Bellani F, et al. Second malignant neoplasms in children. An update from the late effects study group. J Clin Oncol 1985; 3: 532-8.

11 Ellsworth RM. Retinoblastoma. In: Duane TD, ed. Clinical ophthalmology. Philadelphia: Harper and Row, 1985: 3: chapter 35: 2.

12 Ulbright TM, Fulling KH, Helveston EM. Astrocytic tumors of the retina. Arch Pathol Lab Med 1984; 108: 160-3.

Accepted for publication 4 December 1986. 